\section{(6) OPEN ACCESS}

\title{
Spectral-domain optical coherence tomography in subjects over 60 years of age, and its implications for designing clinical trials
}

\author{
Albert Caramoy, ${ }^{1}$ Jonathan Foerster, ${ }^{1}$ Elvira Allakhiarova, ${ }^{1}$ Carel B Hoyng, ${ }^{2}$ \\ Katharina Dröge, ${ }^{1}$ Bernd Kirchhof, ${ }^{1}$ Sascha Fauser ${ }^{1}$
}

${ }^{1}$ Department of Vitreo-Retinal Surgery, Center of Ophthalmology, University of Cologne, Cologne, Germany ${ }^{2}$ Department of Ophthalmology, Radboud University Nijmegen Medical Centre, Nijmegen, The Netherlands

\section{Correspondence to} Dr Albert Caramoy, Department of Vitreo-Retinal Surgery, Center of Ophthalmology, University of Cologne, Kerpener Strasse 62, Cologne 50924,

Germany;

acaramoy@yahoo.co.uk

Accepted 11 July 2012

\section{ABSTRACT}

Aims To study the variability of central retinal thickness (CRT), its concordance to the fellow eye, and the implications for designing future clinical trials using spectral-domain optical coherence tomography (SD-OCT). Methods Cross-sectional retrospective analysis of European Genetic Database. 632 eyes of 316 subjects over 60 years of age without macular pathology were examined using SD-OCT.

Results Mean CRT was $280.22 \mu \mathrm{m}$ and $281.02 \mu \mathrm{m}$ for the right and left eyes, respectively. There was a strong concordance for all measured values between right and left eyes. Men had significantly thicker CRT than women. Variation up to $23 \mu \mathrm{m}$ difference between both eyes was seen. To detect a change of at least $30 \mu \mathrm{m}$ in CRT, a sample size of 90 or 176 per group is needed for a single-arm or double-arm study, respectively $(\alpha=0.05$, power $=0.80$, no loss to follow up, assuming SD in future studies $=100 \mu \mathrm{m})$.

Conclusions Clinical trials using CRT as an endpoint are feasible in terms of sample size needed.

\section{INTRODUCTION}

Measurements of retinal thickness using spectraldomain optical coherence tomography (SD-OCT) are gaining more importance in clinical trials. While visual acuity is usually chosen as the primary endpoint, optical coherence tomography measurements are added as a morphological marker. The development of SD-OCT equipped with an eye-tracking system has increased the reliability of retinal thickness measurements. ${ }^{1} 2$ However, little is known about the variability of retinal thickness in normal individuals. Reliable values would help to estimate sample size more precisely. The use of the fellow eye for comparison also requires exact data on the concordance of both eyes in SD-OCT.

In certain clinical trials, using SD-OCT to assess retinal thickness helps to evaluate the effectiveness of a drug or the severity of the disease progression more precisely. SD-OCT serves as an objective morphological parameter. Most trials on age-related macular degeneration (AMD) and diabetic retinopathy include SD-OCT measurements.

Several studies on macular thickness using SD-OCT have shown that SD-OCT parameters are influenced by age, gender and axial length. ${ }^{3} 4$ Therefore, it is logical to study whether fellow eyes of the same individuals can be used as controls as well. To understand the role of fellow eyes, we determined the central retinal thickness (CRT) in SD-OCT in both eyes of eye-healthy persons aged
60 years and older in a large cohort. This age group is of particular interest in many age-related ophthalmological clinical trials, which utilise SD-OCT measurements.

\section{PATIENTS AND METHODS}

Subjects were recruited in Cologne, Germany, between June 2009 and June 2011. They were participants in the European Genetic Database which is a German/Dutch project studying the development and therapy of AMD. The study followed the tenets of the Declaration of Helsinki, and was reviewed and approved by the local institutional review board. All participants provided written informed consents.

Main inclusion criterion for the analysis was a best-corrected visual acuity (BCVA) better than 20/25 in both eyes. Exclusion criteria included signs of other ocular disease compromising retinal thickness, such as early or late AMD, macular pucker, macular hole, vitreomacular traction, glaucoma, diabetic macular oedema and so on. All subjects underwent full ophthalmic examinations including BCVA measurement, slit lamp examination, binocular indirect ophthalmoscopy, fundus photography, and SD-OCT. Subjects with insufficient quality of SD-OCT images were excluded from the analysis.

SD-OCT was done using Spectralis HRA+OCT (Heidelberg Engineering, Heidelberg, Germany). It included the acquisition of near-infrared fundus reflectance $(\lambda=830 \mathrm{~nm})$. The high-resolution SD-OCT had an acquisition speed of 40000 A-scans. The eye tracker allowed point-to-point correlation of near-infrared fundus reflectance and SD-OCT. For each eye, two OCT scan patterns were performed: (1) a block containing $37 \mathrm{~B}$-scans $\left(20^{\circ} \times 15^{\circ}\right.$, distance between B-scans: $125 \mu \mathrm{m}$ ) and (2) a star of six B-scans (angle between scans was $30^{\circ}$ ).

\section{Analysis of retinal thickness}

SD-OCT was carried out using Heidelberg Eye Explorer software (V.1.7.0.0., Heidelberg Engineering, Heidelberg, Germany). Retinal thickness was defined by the automated segmentation as the distance between the first signal from the vitreoretinal interface and the signal from the posterior boundary of the outermost high-reflective band that presumably correlates with Bruch's membrane. Using this retinal thickness, a thickness map was produced. A clinically significant macular oedema (CSME) grid was used, as described in Campbell et al..$^{5}$ This grid contained three rings, each having a radius of $0.5 \mathrm{~mm}, 1.11 \mathrm{~mm}$ 
and $1.73 \mathrm{~mm}$, respectively, from the centre of the fovea. Using this grid, the macula was divided into nine sectors (figure 1). The CSME grid was manually centred to the centre of the fovea, and segmentation failure was manually corrected.

\section{Statistical analysis and sample size calculation}

Statistical analyses were carried out using PASW Statistics 18 (Predictive Analytics Software, V.18.0.0). Demographic characteristics of the population are described with summary statistics, including frequency and percentage for categorical data. Continuous data are presented with mean $\pm S D$. Student $t$ test for dependent variables is used when comparing the right and left eyes. The concordance of macular measurements between the right and left eyes was also evaluated using the concordance correlation coefficient $\left(\mathrm{r}_{\mathrm{c}}\right)$. ${ }^{6}$ The CRT concordance of the same individual was additionally analysed using Bland-Altman plot. ${ }^{7}$ Both $r_{c}$ and Bland-Altman plot were calculated using MedCalc Software (Mariakerke, Belgium).

Comparison between eyes of different subjects was done using a Student $t$ test for independent variables. p Value $<0.05$ was deemed as statistically significant. All correlations between two values are presented as Pearson product-moment correlation coefficient $(r)$. The partial correlation coefficient between macular measurements and age, spherical refraction and BCVA was calculated using averaged macular measurements of the right and left eyes.

Sample size calculations were done using the G*Power 3 software (available at www.psycho.uni-duesseldorf.de/abteilungen/ aap/gpower3/download-and-register). The software is described and developed by Faul et al. ${ }^{8} 9$ Sample size calculations for all hypothetical studies are carried out using the assumption $\alpha=0.05$, power $=0.8$ and no loss to follow up. ${ }^{10}$

\section{RESULTS}

We enrolled 632 eyes of 316 subjects for this analysis. The main demographic characteristics of these subjects are shown in table 1. Among them were 133 men and 183 women. No significant difference was found in the baseline characteristics of the spherical refraction and visual acuity in logarithm of the minimum angle of resolution ( $\log M A R$ ) between both eyes ( $t$ test for dependent variables, 2 -sided; $p=0.99$ and $p=0.09$, respectively).

Age correlated negatively with all macular measurements, except CRT, after adjusted for gender, spherical refraction and
BCVA (table 2). These correlations are, however, relatively weak. Spherical refraction and BCVA had no significant influence on macular thickness measurements. CRT was the most robust parameter; it was not influenced by age and spherical refraction in this study. In men, CRT was thicker compared with women $(p=0.001)$ (table 3$)$. In macular volume, however, these gender differences were not statistically significant $(p=0.299)$.

\section{Concordance between eyes}

The retinal morphometrics in all nine subfields in CSME grid are shown in table 3. Overall, there was a high concordance of all measured values between the right and left eyes, but there was a significant difference in the CRT, the superior inner, and the superior outer macular thickness between both eyes ( $p$ value $=0.01,0.03$, and $<0.001$, respectively). In myopic eyes (spherical refraction more than -1 diopter), the difference of CRT between right eyes and left eyes was $-1.64 \pm 4.30 \mu \mathrm{m}$ $(p=0.02)$. In hyperopic eyes (spherical refraction more than +1 diopter), the difference of both CRTs was $0.79 \pm 5.57 \mu \mathrm{m}$ and was not statistically significant $(p=0.08)$. The CRT difference between the right and left eyes was not correlated with difference in spherical refraction $(r=0.015, p=0.801)$.

The Bland-Altman plot of CRT between the right and left eyes is depicted in figure 2. The mean difference between the right and left eyes was $-0.8 \mu \mathrm{m}$ (95\% CI from -1.45 to $-0.14 \mu \mathrm{m})$, that is, there is no obvious systematic bias in the CRT differences. The CRT differences are also not dependent on the CRT values.

\section{Analysis of outliers in retinal thickness difference}

The concordance of the CRT between both eyes was perfect in 29 of 316 subjects. In 201 subjects, the difference in CRT was between $1 \mu \mathrm{m}$ and $9 \mu \mathrm{m}$, and in 36 subjects the CRT difference was between $10 \mu \mathrm{m}$ and $23 \mu \mathrm{m}$. The mean absolute CRT difference for all subjects was $0.79 \pm 5.88 \mu \mathrm{m}$ (range $0-23$ ). In patients with a difference of CRT of $>=15 \mu \mathrm{m}$, this difference could not be attributed to spherical refraction, lens status or vitreous adherence.

\section{Sample size calculation}

For designing future clinical trials using retinal thickness measurements in SD-OCT as one possible primary endpoint, one

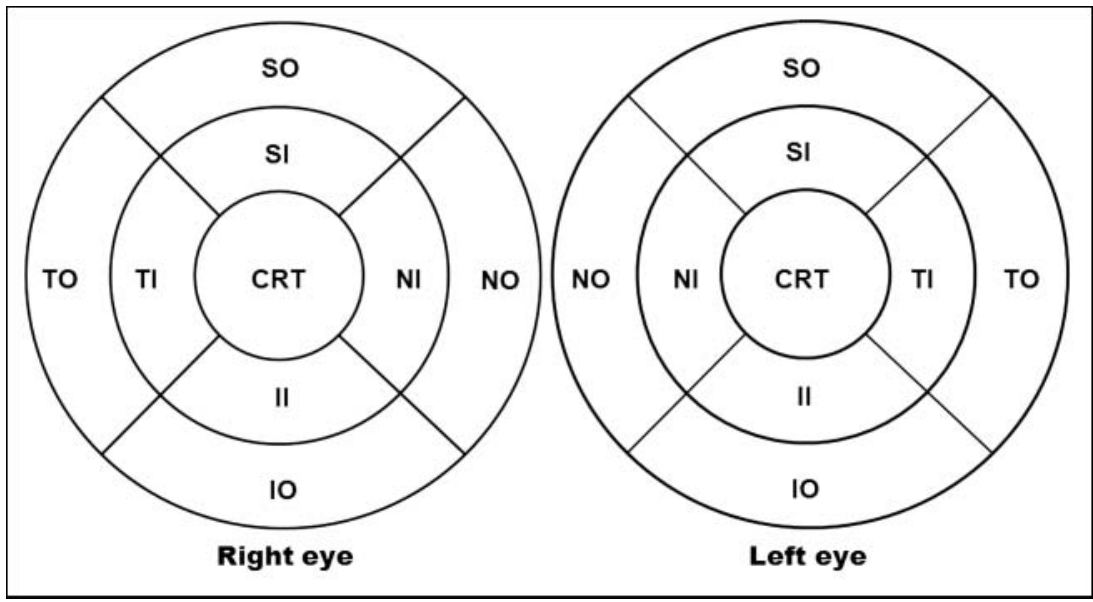

Figure 1 Clinically significant macular oedema grid for both eyes used in this study. The central circle has the radius of $0.5 \mathrm{~mm}$, the middle circle $1.11 \mathrm{~mm}$, and the outermost circle $1.73 \mathrm{~mm}$. CRT, central retinal thickness; SI, superior inner; NI, nasal inner; II, inferior inner; TI, temporal inner; SO, superior outer; NO, nasal outer; IO, inferior outer; TO, temporal outer. 
Table 1 Demographic characteristics

\begin{tabular}{|c|c|c|}
\hline Variables & Value $($ mean $\pm S D)$ & \\
\hline Gender & 133 men, 183 women & \\
\hline Arterial hypertension & $149(47.15 \%)$ & \\
\hline Type 2 diabetes mellitus & $18(5.70 \%)$ & \\
\hline Conditions after stroke & $7(2.22 \%)$ & \\
\hline Hyper- or hypothyreosis & $63(19.94 \%)$ & \\
\hline Oesophageal reflux & $5(1.58 \%)$ & \\
\hline Migraine & $16(5.06 \%)$ & \\
\hline Psoriasis & $8(2.53 \%)$ & \\
\hline Rheumatoid arthritis & $10(3.16 \%)$ & \\
\hline Cardiac dysrhythmia or other cardiac valve diseases & $22(6.96 \%)$ & \\
\hline Other malignancies & $36(11.39 \%)$ & \\
\hline \multirow[t]{2}{*}{ Other surgeries } & $17(5.38 \%)$ & \\
\hline & Right eye & Left eye \\
\hline Spherical refraction (diopter) & $0.83 \pm 2.00$ (range $-6.25-6.00)$ & $0.83 \pm 2.06$ (range $-7.50-7.00$ ) \\
\hline Best corrected visual acuity (LogMAR) & $0.02 \pm 0.05$ (range $-0.20-0.10$ ) & $0.02 \pm 0.05$ (range $-0.20-0.10$ ) \\
\hline Lens status $\mathrm{n}(\%)$ & $\begin{array}{l}303(95.90 \%) \text { phakic } \\
13(4.10 \%) \text { pseudophakic }\end{array}$ & $\begin{array}{l}303(95.90 \%) \text { phakic } \\
13(4.10 \%) \text { pseudophakic }\end{array}$ \\
\hline Vitreous attachment to fovea $\mathrm{n}(\%)$ & $\begin{array}{l}47(14.90 \%) \text { detached } \\
269(85.10 \%) \text { attached }\end{array}$ & $\begin{array}{l}57(18.00 \%) \text { detached } \\
259(82.00 \%) \text { attached }\end{array}$ \\
\hline
\end{tabular}

${ }^{*}$ Multiple diagnosis for one subject possible.

tOnly for male subjects. Percentage calculated only for men.

LogMAR, logarithm of the minimum angle of resolution.

must define the sample size needed. In this study, we found retinal thickness differences of up to $23 \mu \mathrm{m}$ in normal individuals between both eyes. Therefore, a $30 \mu \mathrm{m}$ threshold was chosen for the detection of macular oedema. Assuming a hypothetical study to detect at least a $30 \mu \mathrm{m}$ difference using the fellow eye as a control without a prior SD-OCT measurement, a sample size calculation was done for either single-arm or double-arm studies (table 4). In a double-arm study, the $30 \mu \mathrm{m}$ interindividual CRT differences were chosen, because this value lies outside the $95 \%$ CI (278.393 to $282.844 \mu \mathrm{m})$ and outside the $99 \%$ CI (277.687 to $283.550 \mu \mathrm{m})$ for the averaged CRT of the right and left eye (mean 280.619 \pm SD $20.108 \mu \mathrm{m}$ ).

The sample size calculation for a single-arm study was based on the aforementioned finding that CRT variation between the right and left eye might exist up to $23 \mu \mathrm{m}$. Therefore, a $30 \mu \mathrm{m}$ CRT difference to detect between both eyes is selected. Unlike in the aforementioned calculations for a double-arm study, this threshold for a single-arm study is based on assumption according to cases suggesting that differences less than $30 \mu \mathrm{m}$ might not be clinically relevant. ${ }^{11}$

Table 2 Partial correlation between macular measurements and age, spherical refraction and best corrected visual acuity (BCVA)

\begin{tabular}{|c|c|c|c|c|c|c|}
\hline \multirow[b]{2}{*}{ Variables } & \multicolumn{2}{|l|}{ Age } & \multicolumn{2}{|c|}{ Spherical refraction } & \multicolumn{2}{|l|}{ BCVA } \\
\hline & $r^{*}$ & $\mathbf{p}^{*}$ & $r t$ & pt & $r \neq$ & $\mathbf{p} \ddagger$ \\
\hline Macular volume & -0.208 & 0.000 & 0.125 & 0.032 & -0.077 & 0.187 \\
\hline Superior inner macular thickness & -0.171 & 0.003 & 0.127 & 0.029 & -0.072 & 0.218 \\
\hline Nasal inner macular thickness & -0.153 & 0.009 & 0.118 & 0.044 & -0.057 & 0.328 \\
\hline Inferior inner macular thickness & -0.159 & 0.007 & 0.106 & 0.070 & -0.067 & 0.251 \\
\hline Nasal outer macular thickness & -0.221 & 0.000 & 0.117 & 0.045 & -0.095 & 0.105 \\
\hline Inferior outer macular thickness & -0.201 & 0.001 & 0.136 & 0.020 & -0.081 & 0.165 \\
\hline Temporal outer macular thickness & -0.224 & 0.000 & 0.144 & 0.013 & -0.085 & 0.147 \\
\hline
\end{tabular}

For this purpose, measurements from the right eye and the left eye for each individual were averaged

${ }^{*}$ Adjusted for sex, spherical refraction and BCVA.

†Adjusted for sex, age and BCVA.

$\ddagger$ Adjusted for sex, age and spherical refraction. 
Table 3 Retinal thickness measurements

\begin{tabular}{|c|c|c|c|c|c|c|c|c|c|}
\hline \multirow[b]{2}{*}{ Variables } & \multicolumn{3}{|l|}{ Overall } & \multicolumn{3}{|l|}{ Men } & \multicolumn{3}{|l|}{ Women } \\
\hline & Right eye & Left eye & $\begin{array}{l}\mathrm{p}^{*} \\
\mathrm{r}^{\dagger} \\
\mathrm{r}_{\mathrm{c}}\end{array}$ & Right eye & Left eye & $\begin{array}{l}p^{*} \\
r^{\prime} \\
r_{c}\end{array}$ & Right eye & Left eye & $\begin{array}{l}p^{*} \\
r^{\prime} \\
r_{c}\end{array}$ \\
\hline Central retinal thickness $(\mathrm{CRT})(\mu \mathrm{m})$ & $280.22 \pm 20.17$ & $281.02 \pm 20.47$ & $\begin{array}{l}0.017 \\
0.958 \\
0.957\end{array}$ & $287.40 \pm 19.54$ & $288.40 \pm 20.24$ & $\begin{array}{l}0.078 \\
0.947 \\
0.946\end{array}$ & $275.01 \pm 19.03$ & $275.65 \pm 18.97$ & $\begin{array}{l}0.108 \\
0.959 \\
0.959\end{array}$ \\
\hline Superior inner macular thickness $(\mu \mathrm{m})$ & $343.64 \pm 15.23$ & $344.45 \pm 15.22$ & $\begin{array}{l}0.035 \\
0.902 \\
0.900\end{array}$ & $343.56 \pm 16.53$ & $344.57 \pm 17.04$ & $\begin{array}{l}0.088 \\
0.919 \\
0.917\end{array}$ & $343.70 \pm 14.26$ & $344.36 \pm 13.80$ & $\begin{array}{l}0.191 \\
0.884 \\
0.883\end{array}$ \\
\hline Nasal inner macular thickness $(\mu \mathrm{m})$ & $341.63 \pm 15.92$ & $342.28 \pm 15.81$ & $\begin{array}{l}0.073 \\
0.916 \\
0.915\end{array}$ & $343.68 \pm 16.94$ & $344.50 \pm 18.11$ & $\begin{array}{l}0.167 \\
0.927 \\
0.924\end{array}$ & $340.14 \pm 15.00$ & $340.68 \pm 13.74$ & $\begin{array}{l}0.248 \\
0.907 \\
0.903\end{array}$ \\
\hline Superior outer macular thickness $(\mu \mathrm{m})$ & $329.77 \pm 15.68$ & $331.28 \pm 16.25$ & $\begin{array}{l}0.000 \\
0.909 \\
0.904\end{array}$ & $325.63 \pm 15.58$ & $327.04 \pm 16.03$ & $\begin{array}{l}0.043 \\
0.875 \\
0.871\end{array}$ & $332.77 \pm 15.10$ & $334.36 \pm 15.74$ & $\begin{array}{l}0.000 \\
0.926 \\
0.920\end{array}$ \\
\hline Nasal outer macular thickness $(\mu \mathrm{m})$ & $339.69 \pm 15.62$ & $340.21 \pm 15.77$ & $\begin{array}{l}0.143 \\
0.920 \\
0.920\end{array}$ & $336.31 \pm 15.82$ & $336.85 \pm 16.76$ & $\begin{array}{l}0.340 \\
0.922 \\
0.920\end{array}$ & $342.15 \pm 15.05$ & $342.65 \pm 14.58$ & $\begin{array}{l}0.268 \\
0.915 \\
0.914\end{array}$ \\
\hline Inferior outer macular thickness $(\mu \mathrm{m})$ & $326.52 \pm 15.52$ & $326.33 \pm 16.20$ & $\begin{array}{l}0.665 \\
0.885 \\
0.884\end{array}$ & $322.58 \pm 14.98$ & $322.26 \pm 16.16$ & $\begin{array}{l}0.625 \\
0.889 \\
0.886\end{array}$ & $329.38 \pm 15.32$ & $329.29 \pm 15.62$ & $\begin{array}{l}0.873 \\
0.872 \\
0.872\end{array}$ \\
\hline Temporal outer macular thickness $(\mu \mathrm{m})$ & $324.58 \pm 14.51$ & $324.63 \pm 15.10$ & $\begin{array}{l}0.880 \\
0.909 \\
0.909\end{array}$ & $322.44 \pm 14.78$ & $322.72 \pm 15.59$ & $\begin{array}{l}0.608 \\
0.917 \\
0.915\end{array}$ & $326.13 \pm 14.14$ & $326.02 \pm 14.62$ & $\begin{array}{l}0.817 \\
0.902 \\
0.901\end{array}$ \\
\hline
\end{tabular}

*Two-sided $\mathrm{t}$ test for dependent variables,

†Pearson correlation coefficient.

$r_{c}$, concordance correlation coefficient. Confer figure 1 for the variables used.

Although CRT SD of $20 \mu \mathrm{m}$ is found in our study, the actual $\mathrm{SD}$ in a future study taken collectively might vary considerably, that is, it depends on the art of surgery or treatment being studied. Therefore, sample sizes for various SDs are presented.

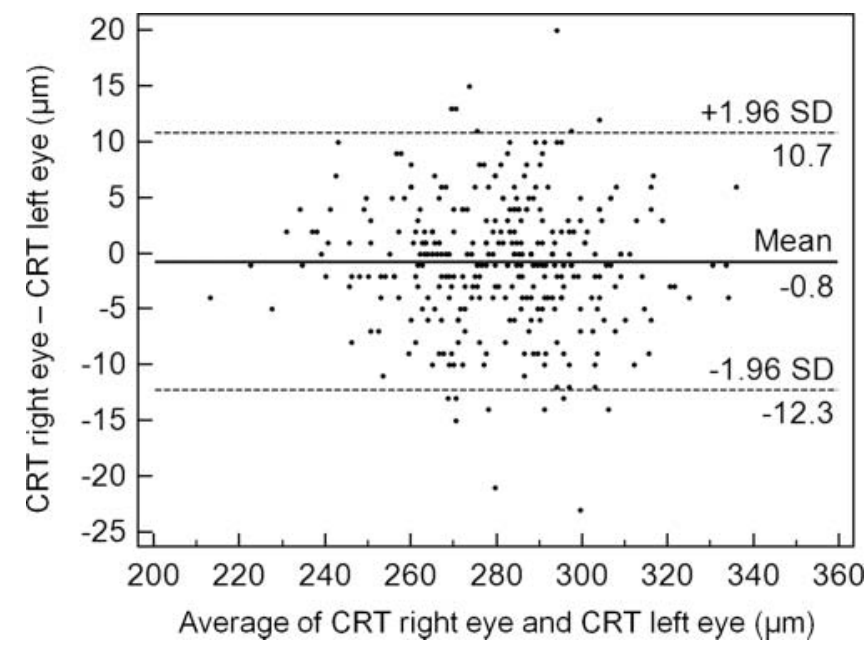

Figure 2 Bland-Altman plot of central retinal thickness between the right and left eyes.

\section{DISCUSSION}

Some authors have examined the characteristics of retinal thickness using SD-OCT. A study by Song et al ${ }^{\beta}$ using Cirrus HD-OCT described that retinal thickness of one randomly

Table 4 Sample size calculations

\begin{tabular}{|c|c|c|c|c|c|}
\hline \multirow[b]{2}{*}{ Type of study } & \multicolumn{5}{|c|}{ Total patients required, using standard deviation of } \\
\hline & $20^{12}$ & $50^{13}$ & $100^{1314}$ & $200^{15}$ & $300 *$ \\
\hline $\begin{array}{l}\text { Uniocular surgery or } \\
\text { treatment using fellow } \\
\text { eye as control (one } \\
\text { group) } \dagger\end{array}$ & 6 & 24 & 90 & 351 & 787 \\
\hline $\begin{array}{l}\text { Two groups of } \\
\text { uniocular surgery or } \\
\text { treatment } \ddagger\end{array}$ & $\begin{array}{l}18 \text { (9 } \\
\text { per } \\
\text { group) }\end{array}$ & $\begin{array}{l}90 \text { (45 } \\
\text { per } \\
\text { group) }\end{array}$ & $\begin{array}{l}352 \text { (176 } \\
\text { per group) }\end{array}$ & $\begin{array}{l}1398 \\
\text { (699 per } \\
\text { group) }\end{array}$ & $\begin{array}{l}3142 \\
\text { (1571 per } \\
\text { group) }\end{array}$ \\
\hline
\end{tabular}

$\alpha=0.05$, power $=0.8$ for all calculations.

Difference to detect is $30 \mu \mathrm{m}$ CRT, either to the fellow eye or to other treatment/ surgery group. Assuming none lost to follow-up. Examples of literatures using the mentioned SDs are also given.

* Based on literatures that severe cases of diabetic macular oedema might exhibit CRT up to $600 \mu \mathrm{m}$, leading to a total SD of approximately $300 \mu \mathrm{m} .^{16}$

tAt -test for comparing difference between two dependent means (matched pairs), for example, study assessing impact of phacoemulsification on the retina in comparison with the fellow eye.

$\ddagger$ At test for comparing difference between two independent means (two groups), for example, study assessing two phacoemulsification types. 
selected eye of 198 individuals decreases with age. This concurs with our findings, in that we also found a weak negative correlation between macular thickness measurements and age even after adjustments for sex, spherical refraction and BCVA (table 2). This might be due to a decrease in the density of ganglion cells, photoreceptors and retinal pigment epithelium cells brought on with age, which was shown in histology. ${ }^{17} 18$ The decrease in the macular thickness with age was found for all subfields except for the central fovea (CRT), where we found no change with age. This was in line with the findings within the study by Song et $a l^{3}$ in which the central subfield thickness was not correlated with age. Correspondingly, histopathological studies found a stable cone density in the fovea, when compared with rods. ${ }^{19} 20$

Men had a significantly thicker CRT compared with women, which is in line with other studies 342122 Only Sabates et al ${ }^{23}$ found no differences in mean macular thickness with regard to gender, but they examined the mean retinal thickness as opposed to CRT in our study. In contrast to CRT, we found no statistical differences in macular volume between men and women. These gender differences have to be taken into consideration in analysing future clinical trials if two different study arms with imbalance in gender proportions are compared.

Although CRT was not influenced by age and refractive error (table 2), we found intraindividual differences between both eyes in myopia. Although these differences were relatively small (mean $-1.64 \pm 4.30 \mu \mathrm{m}$ ), this has to be kept in mind when CRT of myopic eyes of the same individuals are compared.

Overall, there was a strong concordance of CRT between both eyes. In clinical trials involving interventions of only one eye, it is possible to use CRT of the fellow eye as a control. The sample size needed to rule out a statistically significant difference is relatively small, that is, 90 patients or 352 patients for a single-arm or double-arm studies, respectively (table 4). The CRT difference between both eyes in this study does not correlate with difference in spherical refractive error, indicating that the differences in CRT between both eyes is not influenced by spherical refraction differences between both eyes. They represent the natural variations in one individual.

Among many others, one useful application of CRT measurements is for detecting macular oedema. In many cases, macular oedema is characterised by intraretinal fluid, that is, cysts or subretinal fluid that can be easily detected using SD-OCT. However, there are cases, in which no fluid is seen on SD-OCT. This vision-relevant macular oedema can only be detected by means of fluorescein angiography, or by measuring the thickening of the fovea by SD-OCT. ${ }^{11}$ Because fluorescein angiography is an invasive method, using other non-invasive methods for detecting subtle macular oedema might be beneficial. In this case, measurements of CRT using SD-OCT would be appropriate. Our calculations show that the sample size needed to detect such changes is relatively small.

Most clinical trials relied on visual acuity change as the primary outcome measure of treatment efficacy. In some conditions, however, retinal thickness measurement might even improve the validity of the study. In the example of pseudophakia-associated macular oedema stated above, the disease severity might be underestimated if visual acuity was used as an outcome measure alone. In assessing the eye after cataract surgery, the visual acuity might improve, however, if macular oedema occurred, it might be undervalued. Also in clinical trials, assessing the effect of cataract-inducing drugs, such as corticosteroids in diabetic macular oedema, ${ }^{24} 25$ macular oedema due to uveitis, ${ }^{26}$ central retinal vein occlusion, or branch retinal vein occlusion, using retinal thickness measurements would enhance the informative value of the study if the informative value of BCVA change is restricted due to media opacity.

The strength of our study relies on the relatively large number of subjects. However, there are also some drawbacks, such as the retrospective nature of the analysis and, therefore, prone to bias of uncertain kind. The sample size calculations performed in our study are based on CRT differences and, therefore, suitable for future studies assessing macular oedema involving the fovea or the centre of the macula. The parameters to be used in calculations for studies with respect to macular oedema not involving the fovea are yet to be determined.

In this study, we have provided standard values of persons 60 years of age and older. CRT proved to be a robust parameter not influenced by age and refractive error. The intraindividual difference between both eyes was small. These data will help to design clinical trials with SD-OCT measurements.

Contributors Study conception and design: AC, SF; data acquisition: AC, JF, EA, KD; analysis and interpretation of the data: $\mathrm{AC}, \mathrm{SF}, \mathrm{BK}, \mathrm{CBH}$; drafting and revising the article: AC, JF, EA, CBH, KD, BK, SF; final approval: AC, JF, EA, CBH, KD, BK, SF.

Competing interests None.

Patient consent Obtained.

Ethics approval Ethics Committee, University of Cologne, Germany.

Provenance and peer review Not commissioned; externally peer reviewed.

\section{REFERENCES}

1. Jo YJ, Heo DW, Shin Yl, et al. Diurnal variation of retina thickness measured with time domain and spectral domain optical coherence tomography in healthy subjects. Invest Ophthalmol Vis Sci 2011;52:6497-500

2. Wolf-Schnurrbusch UE, Ceklic L, Brinkmann CK, et al. Macular thickness measurements in healthy eyes using six different optical coherence tomography instruments. Invest Ophthalmol Vis Sci 2009:50:3432-7.

3. Song WK, Lee SC, Lee ES, et al. Macular thickness variations with sex, age, and axial length in healthy subjects: a spectral domain-optical coherence tomography study. Invest Ophthalmol Vis Sci 2010;51:3913-18.

4. Ooto S, Hangai M, Tomidokoro A, et al. Effects of age, gender, and axial length on the three-dimensional profile of normal macular layer structures. Invest Ophthalmol Vis Sci 2011;52:8769-79.

5. Campbell RJ, Coupland SG, Buhrmann RR, et al. Optimal optical coherence tomography-based measures in the diagnosis of clinically significant macular edema: retinal volume vs foveal thickness. Arch Ophthalmol 2007;125:619-23.

6. Lin LI. A concordance correlation coefficient to evaluate reproducibility. Biometrics 1989;45:255-68.

7. Bland JM, Altman DG. Measuring agreement in method comparison studies. Stat Methods Med Res 1999;8:135-60.

8. Faul F, Erdfelder $\mathrm{E}$, Lang $A G$, et al. G*Power 3: a flexible statistical power analysis program for the social, behavioral, and biomedical sciences. Behav Res Methods 2007;39:175-91.

9. Faul F, Erdfelder E, Buchner A, et al. Statistical power analyses using G*Power 3.1: tests for correlation and regression analyses. Behav Res Methods 2009;41:1149-60.

10. Gauderman WJ, Barlow WE. Sample size calculations for ophthalmologic studies. Arch Ophthalmol 1992;110:690-2

11. Caramoy A, Fauser S, Kirchhof B, et al. (A case report of two patients with pseudophakia-associated macular edema: can OCT replace fluorescein angiography?). Klin Monbl Augenheilkd 2009;226:849-51.

12. Kusbeci T, Eryigit L, Yavas G, et al. Evaluation of cystoid macular edema using optical coherence tomography and fundus fluorescein angiography after uncomplicated phacoemulsification surgery. Curr Eye Res 2012;37:327-33.

13. Ophir A, Martinez MR. Epiretinal membranes and incomplete posterior vitreous detachment in diabetic macular edema, detected by spectral-domain optical coherence tomography. Invest Ophthalmol Vis Sci 2011;52:6414-20.

14. Chung H, Park B, Shin HJ, et al. Correlation of fundus autofluorescence with spectral-domain optical coherence tomography and vision in diabetic macular edema. Ophthalmology 2012;119:1056-65.

15. Martinez MR, Ophir A. Extrafoveal traction in retinal vein occlusion using spectral domain optical coherence tomography. Graefes Arch Clin Exp Ophthalmol 2011;249:811-20. 
16. Koleva-Georgieva D, Sivkova N. Assessment of serous macular detachment in eyes with diabetic macular edema by use of spectral-domain optical coherence tomography. Graefes Arch Clin Exp Ophthalmol 2009:247:1461-9.

17. Panda-Jonas S, Jonas JB, Jakobczyk-Zmija M. Retinal photoreceptor density decreases with age. Ophthalmology 1995;102:1853-9.

18. Gao H, Hollyfield JG. Aging of the human retina. Differential loss of neurons and retinal pigment epithelial cells. Invest Ophthalmol Vis Sci 1992;33:1-17.

19. Curcio CA, Millican CL, Allen KA, et al. Aging of the human photoreceptor mosaic: evidence for selective vulnerability of rods in central retina. Invest Ophthalmol Vis Sci 1993;34:3278-96.

20. Curcio CA. Photoreceptor topography in ageing and age-related maculopathy. Eye (Lond) 2001:15(Pt 3):376-83.

21. Wong AC, Chan CW, Hui SP. Relationship of gender, body mass index, and axial length with central retinal thickness using optical coherence tomography. Eye (Lond) 2005; 19:292-7.
22. Massin P, Erginay A, Haouchine B, et al. Retinal thickness in healthy and diabetic subjects measured using optical coherence tomography mapping software. Eur J Ophthalmol 2002;12:102-8.

23. Sabates FN, Vincent RD, Koulen P, et al. Normative data set identifying properties of the macula across age groups: integration of visual function and retinal structure with microperimetry and spectral-domain optical coherence tomography. Retina 2011;31:1294-302.

24. Chew EY, Glassman AR, Beck RW, et al. Ocular side effects associated with peribulbar injections of triamcinolone acetonide for diabetic macular edema. Retina 2011:31:284-9

25. Beck RW, Edwards AR, Aiello LP, et al. Three-year follow-up of a randomized trial comparing focal/grid photocoagulation and intravitreal triamcinolone for diabetic macular edema. Arch Ophthalmol 2009;127:245-51.

26. Taylor SR, Isa H, Joshi L, et al. New developments in corticosteroid therapy for uveitis. Ophthalmologica 2010;224(Suppl 1):46-53. 